\title{
La planta del río Amazonas desde Quito hasta su desembocadura elaborada por Benito de Acosta y otros mapas
}

Fragmentos seleccionados de los "Preliminares" de Marcos Jiménez de la Espada a su Viaje del capitán Pedro Texeira aguas arriba del río de las Amazonas (1638-1639) (1889)

\section{Marcos Jiménez de la Espada}

\section{(2) OpenEdition}

\section{Electronic version}

URL: https://journals.openedition.org/terrabrasilis/6974

DOI: $10.4000 /$ terrabrasilis. 6974

ISSN: 2316-7793

\section{Publisher}

Rede Brasileira de História da Geografia e Geografia Histórica

\section{Electronic reference}

Marcos Jiménez de la Espada, "La planta del río Amazonas desde Quito hasta su desembocadura elaborada por Benito de Acosta y otros mapas", Terra Brasilis [Online], 14 | 2020, Online since 31 December 2020, connection on 05 December 2022. URL: http://journals.openedition.org/terrabrasilis/ 6974 ; DOI: https://doi.org/10.4000/terrabrasilis.6974

This text was automatically generated on 5 December 2022.

All rights reserved 


\section{La planta del río Amazonas desde Quito hasta su desembocadura elaborada por Benito de Acosta y otros mapas}

Fragmentos seleccionados de los "Preliminares" de Marcos Jiménez de la Espada a su Viaje del capitán Pedro Texeira aguas arriba del río de las Amazonas (1638-1639) (1889)

Marcos Jiménez de la Espada

\section{EDITOR'S NOTE}

Existe en la Biblioteca Nacional de España un importante manuscrito anónimo en 31 folios titulado Descubrimiento del río de las Amazonas y sus dilatadas Provincias, acompañado de uno de los mapas más interesantes, sobresalientes, definitivos y bellos de la historia de la cartografía amazónica -y que destacamos en la portada del presente número de la Terra Brasilis. El manuscrito, datado en 1639, contiene el relato titulado Relación del descubrimiento del río de las Amazonas, hoy S. Francisco del Quito y declaración del mapa donde está pintado, que ofrece algunos detalles del viaje realizado por un grupo de religiosos y soldados españoles desde Quito hasta Belén del Pará y del viaje emprendido en respuesta por la escuadra portuguesa capitaneada por Pedro Teixeira, acontecimientos ocurridos en esos últimos años de la Unión Ibérica y que se irían a mostrar fundamentales para la historia de la definición de los límites entre las dos coronas en el futuro. El historiador español Marcos Jiménez de la Espada, responsable por la publicación y crítica de múltiples e importantes documentos americanos y en particular Amazónicos -además de explorador del río Amazonas, que navegó desde Quito hasta el Pará como parte de la Comisión Científica del Pacífico en 1865-, publicó en 1889 dicho manuscrito y una copia del mapa que lo acompaña, junto con otros documentos, anotaciones y un valioso estudio introductorio bajo el título Viaje del 
Capitán Pedro Texeira Aguas Arriba del Río de las Amazonas (1638-1639) (Madrid: Imprenta de Fortanet, 131 p. [disponible en la Biblioteca Digital Hispánica de la Biblioteca Nacional de España: <http://bdh.bne.es/bnesearch/detalle/bdh0000056812> y en la Biblioteca Brasiliana Guita e José Mindlin de la Universidad de São Paulo <https:// digital.bbm.usp.br/handle/bbm/5026>]) (Figura 1). En estos "Preliminares", que la revista Terra Brasilis reproduce en las partes correspondientes al mapa en cuestión y a los comentarios del autor sobre la cartografía amazónica (páginas 4 a 7, 53 a 63 y 107 a 108), Jiménez atribuye el manuscrito al padre jesuita Alonso de Rojas, entonces rector del Colegio de Quito, y el mapa a un original del piloto de Teixeira Benito de Acosta conocido en portugués como Bento da Costa. El manuscrito de Rojas, a todas luces, recoge relatos tanto de los españoles que bajaron el río como de los portugueses que llegaron a Quito, en particular del piloto de Acosta. De las manos del autor pasó a las de Martín de Saavedra y Guzmán, gobernador de la Nueva Granada, que lo remite a España y que ha sido tomado como el autor del texto (así figura, inclusive, en el catálogo de la Biblioteca Nacional de España). Si bien el relato del padre Rojas llegó a ser publicado en Quito en 1942 con la autoría correspondiente, el mapa, en cambio, siendo más o menos conocido - principalmente en el Ecuador-, continuamente es atribuido erróneamente al citado Saavedra e incluso a veces al padre Cristóbal de Acuña, compañero de Teixeira en el viaje de bajada. Creemos que vale la pena entonces dar nueva vida al texto de Jiménez de la Espada en nuestra sección de Clásicos, no sólo por las atribuciones de autoría allí contenidas, sino también por las interesantes observaciones del autor con respecto a la historia de la cartografía amazónica. Adicionalmente, hemos incorporado al texto del historiador español los mapas por él mencionados, disponibles actualmente para los investigadores en el universo en expansión de las bibliotecas digitales. No puede dejar de mencionarse el libro Pedro Teixeira, a Amazônia e o Tratado de Madri, organizado por Sérgio Eduardo Moreira Lima y Maria do Carmo Strozzi Coutinho (Brasília: Fundação Alexandre de Gusmão, 2016, disponible en la Biblioteca Digital de dicha Fundación <http://funag.gov.br/biblioteca/download/PEDRO-TEIXEIRA_EDICAOCOMPLETA_17_11_V_9_web.pdf>), que, además de otros documentos importantísimos para la interpretación del mapa de Acosta, reproduce el texto del padre Rojas y las notas al pie de Jiménez de la Espada. Llama mucho la atención, como destacado en esta misma obra, incluso con fotografías de su ejemplar, la atención prestada por el Barón de Rio Branco tanto al relato de Rojas como a los comentarios de Jiménez de la Espada, profusamente subrayados, en varios colores y con notas al margen. En cuanto al mapa de Benito de Acosta, no es apenas el primero en presentar observaciones sistemáticas a lo largo del curso del río -como las distancias en leguas y las profundidades en brazas -, sino que, a pesar de ser fruto de las ambiciones y de las rivalidades imperiales, atestigua la estrecha relación histórica entre el río de las Amazonas y la cordillera de los Andes. Localización de las imágenes, leyendas y notas por David Ramírez Palacios.

\section{Preliminares}


Figura 1. Portada de El Viaje del capitán Pedro Texeira de Marcos Jiménez de la Espada

\section{VIAJE}

\section{CAPITÁN PEDRO TEXEIRA}
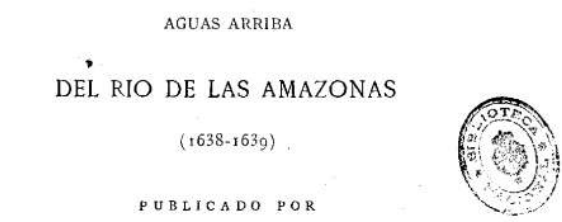

MÁRCOS JIMENEZ DE LA ESPADA

MA D RID

IMPRENTA DE FORTANET

CALLE DE LA LIBERTAD, 29

$\overrightarrow{889}$

Edición elaborada por Jiménez de la Espada del manuscrito de Alonso de Rojas titulado Relación del descubrimiento del río de las Amazonas, hoy S. Francisco del Quito y declaración del mapa donde está pintado (1639), que incluye una reproducción del mapa de Benito de Acosta y otros documentos.

Fuente: Biblioteca Digital Hispánica - Biblioteca Nacional de España. Disponible en: http://bdh.bne.es/ bnesearch/detalle/bdh0000056812

1 No deja de ser extraño que, habiendo inspirado siempre, y con razón, tanto interés los descubrimientos y navegaciones del famoso rio, cuyo nombre primero y ya olvidado fue Santa María de la Mar Dulce, ${ }^{1}$ esté sin publicar todavía el más importante de los documentos que refieren el único viaje de subida que se llevó a cabo con felicidad, y al mando del capitán Pedro Texeira, por tiempos en que las comarcas brasileñas, como el reino lusitano, pertenecían a la corona de España. Verdad es que si todos los que le han visto han formado de él igual concepto que el Sr. D. Eugenio de Ochoa, el caso nada tendría de particular, porque en su Catálogo razonado de los MSS. españoles existentes en la Biblioteca real de París (1844) le describía y calificaba de la manera siguiente:

DESCUBRIMIENTO del rio de las Amazonas con sus dilatadas provincias.

Ms. en $8^{\circ}$, bien conservado, en papel, hojas 32 , letra grande, siglo XVII, muchos ornatos, mayúsculas bordadas y muchos ringorrangos de pésimo gusto y peor ejecución.

Autor de esté ms. fue D. Martin de Saavedra y Guzmán, quien lo envió desde Santa Fé en 23 de Junio de 1639 (según consta de la dedicatoria a D. García de Avellaneda y Haro, conde de Castrillo, Presidente del Consejo Real de las Indias. Compónese [aquí su contenido, indicando que debía acompañar al documento un mapa, y prosigue:] Falta este mapa; sólo se conserva un pequeño pedazo de él ${ }^{2}$ pegado a la parte interior del pergamino en que está encuadernado este ms.: debía ser un verdadero mamarracho, a juzgar por la muestra. Inútil es advertir cuan concisa e incompleta es esta relación, que sólo ocupa (cercenadas de las 32 hojas del ms. siete que llevan los documentos ya citados) 25 hojas en $8^{\circ}$ reducido y de letra muy grande. (Suplemento. - 965-40) 
Pero esta opinión a todas luces es exagerada y parece emitida bajo la influencia del aspecto y trazas del ejemplar y de un pedazo del mamarracho; por lo cual, no temo arrostrarla y oponerla los motivos que tengo para considerar muy importante a la Historia y a la Geografía españolas aquella relación y el mapa que la acompaña, entero por fortuna, en el traslado que de uno y otro se conserva en nuestra Biblioteca Nacional (Q. 196) (Figura 2).

Figura 2. Portada del Descubrimiento de Río de las Amazonas y sus dilatadas provincias (1639)

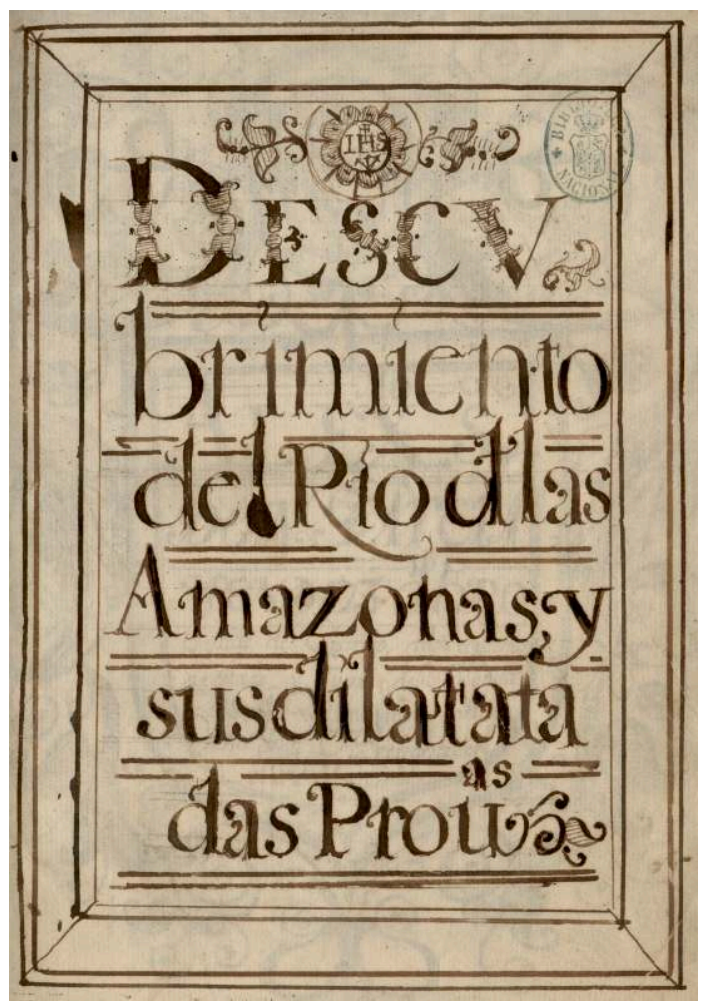

Atribuido por Jiménez de la Espada al jesuita español Alonso de Rojas, entonces rector del Colegio de Quito. Contiene una "Relación del descubrimiento del río de las Amazonas, hoy S. Francisco del Quito y declaración del mapa donde está pintado", así como una copia del mapa elaborado por el piloto portugués de la escuadra de Pedro Teixeira Benito de Acosta (Bento da Costa). Se conserva en la Biblioteca Nacional de España, no bajo la signatura indicada por Jiménez, sino clasificado como Mss/ 5859. En el catálogo de esta biblioteca el manuscrito y el mapa se encuentran erróneamente atribuidos a Martín de Saavedra y Guzmán, entonces gobernador de la Nueva Granada, a quien cupo recibir el documento "por la vía de Quito" y remitirlo a España.

Fuente: Biblioteca Digital Hispánica - Biblioteca Nacional de España. Disponible en: http://bdh.bne.es/ bnesearch/detalle/bdh0000053845

3 Me explico que el señor don Eugenio de Ochoa adjudicase a la persona que más a mano tuvo la paternidad del Descubrimiento del rio de las Amazonas con sus dilatadas provincias, ya que este insigne literato estimaba la obrilla de muy poco valer, y es probable, por ende, que entendiese que lo mismo importaba que la hubiese escrito don Martín de Saavedra y Guzmán, firmante al cabo de la dedicatoria, que otro cualquiera; si no es que temió contradecir al erudito Barcia en sus extensas adiciones al Epitome de León Pinelo, una de las cuales reza: "DON MARTIN DE SAAVEDRA GUZMAN, Descubrimiento del Rio de las Amazonas, i sus dilatadas Provincias, dedicado al Conde de Castrillo, Presidente de Indias, con vn Mapa mui extenso del Rio, i reflexiones para asegurar la Navegación $\mathrm{i}$ la Tierra, M. S. O. en la Librería del Marques de la Compuesta, Secretario del Despacho 
Vniversal". ${ }^{3}$ Lo que no comprendo es que un crítico tan escrupuloso como Mr. MorelFatio, pase ni más ni menos por lo que dijo el señor de Ochoa y por el artículo de Barcia y repita en su Catalogue des manuscrits espagnols de la Bibliothèque nationale (1881), que el autor del Descubrimiento del río de las Amazonas con sus dilatadas provincias es don Martín de Saavedra y Guzmán. Porque, o yo estoy ciego, o basta con abrir el manuscrito por la primera página y leer las primeras líneas de la dedicatoria en que declara don Martín: "Llegó por la vía de Quito a mis manos la relación y planta del río de las Amazonas, etc.;" y no hay que darle vueltas, para llegar a sus manos tuvo que salir de otras. Por consiguiente, a menos que esas otras parezcan o hayan dejado huellas evidentes en algún pasaje del manuscrito $-\mathrm{y}$ yo por más que miro no las veo- éste debió figurar anónimo en los catálogos de los señores Ochoa y Morel-Fatio; y así figurará en nuestra edición, aunque tenga motivos, y de fundamento, para adjudicárselo a más legítimo autor que el presidente de la Audiencia de Santa Fe. Pero en esto de filiaciones literarias a lo mejor tropieza uno con quien menos pensaba, y saludables experiencias me han hecho cauto y receloso.

El licenciado Antonio de León Pinelo, que como he dicho poco ha, entendió por su oficio y encargo especial del Consejo de Indias en el expediente del viaje del P. Cristóbal de Acuña, al describir el río de las Amazonas y sus navegaciones y descubrimientos en el citado libro del Paraíso en el Nuevo Mundo, cuenta aunque más brevemente por los mismos términos que nuestro manuscrito el primer viaje de Pedro Texeira, y añade a seguida: "De que el P. Alonso de Rojas de la Compañía de Jesús escribió una Relación que llegó a mis manos, aunque no el mapa que con ella venía." Agréguese a tan autorizada noticia que la relación dedicada al conde de Castrillo le llegó a don Martín de Saavedra por la vía de Quito; que en esta ciudad residió, y acaso a la sazón era ya rector de su Colegio Máximo, el P. Rojas, ${ }^{4}$ y que el original de que nos servimos lleva la cifra y timbre de la Compañía de Jesús, y véase si todo ello no induce y convida a poner debajo del epígrafe del viaje de Pedro Texeira el nombre de aquel religioso.

Además -y esto constituye una de las curiosidades de nuestro documento-, el P. Cristóbal de Acuña tomó de él a la letra los párrafos $2^{\circ}, 3^{\circ}, 5^{\circ}, 7^{\circ}$ y $8^{\circ}$ y los dio como suyos en los números XX, XXI, XXII y XXIII del Nuevo descubrimiento del gran río, etc., y no me parece que se hubiera atrevido a cometer el plagio, aunque venial -pues se reduce a unos cuantos trozos de pura retórica o de estilo-, sino a sabiendas de que su dueño era de la Compañía de Jesús, y, por lo tanto, lo tomado, en cierto modo, propiedad común dentro de ella.

Me consta que León Pinelo adicionó de su puño un ejemplar de su Epitome de la biblioteca oriental y occidental náutica y geográfica (Madrid MDCXXIX). Acaso allí se encuentra la relación del primer viaje de Texeira con su verdadero autor. ${ }^{5}$ 
Figura 3. Planta del río Amazonas desde Quito hasta su desembocadura, elaborado a partir de un original del piloto Benito de Acosta (c. 1638)

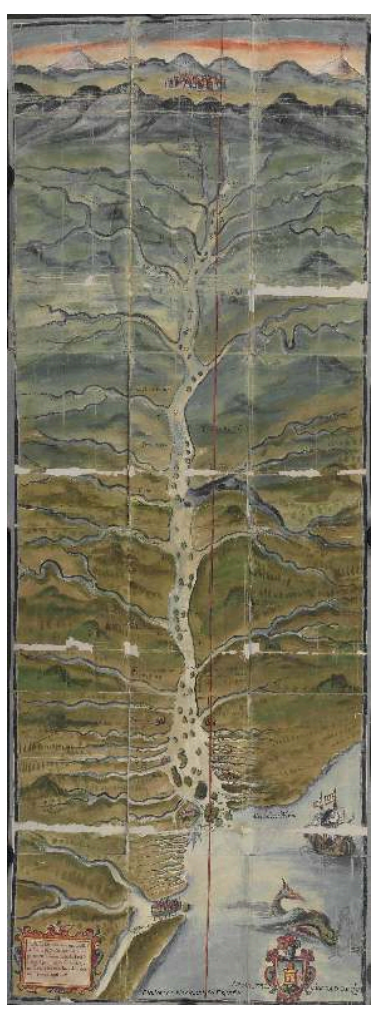

Para Jiménez de la Espada, el mapa que acompaña el manuscrito de Alonso de Rojas debió haber sido realizado siguiendo "un original contemporáneo del viaje que ilustra", con toda probabilidad el trazado por el piloto de la escuadra de Teixeira Benito de Acosta, conocido en portugués como Bento da Costa. En la cartela de la parte inferior izquierda se lee: "Desde las orillas del mar, hasta las tierras de Quito por una y otra parte son innumerables las Provincias que ay, que por ser tantas y no saberse los nombres de todas no se ponen aqui". Este mapa, muy conocido en el Ecuador (obsérvese que lleva el escudo de armas de Quito), ha sido erróneamente atribuido no sólo a Martín de Saavedra y Guzmán -así aparece catalogado en la Biblioteca Nacional de España- sino incluso también al padre Acuña.

Fuente: Biblioteca Digital Hispánica - Biblioteca Nacional de España. Disponible en: http://bdh.bne.es/ bnesearch/detalle/bdh0000199147

7 En idéntico caso que el texto de la dicha relación, se encuentra el mapa o planta que va con ella. ¿Bastará lo dicho por fr. Laureano de la Cruz para atribuírselo con entera seguridad a Benito de Acosta (Figura 3), piloto de la armadilla de Texeira? ${ }^{6}{ }^{\text {No }}$ hizo otro además del mismo río con motivo del mismo viaje y por el mismo tiempo el licenciado don Fernando Montesinos?? Si a la relación -quizá original-del P. Rojas que llegó a manos de Pinelo le faltaba ya la pintura del río que con ella venía, ¿no faltaría con más motivo en los traslados posteriores y se supliría con otra? Todo es posible; pero en lo que no cabe duda es en que la planta del Amazonas correspondiente al MS. Q. 196 de nuestra Biblioteca Nacional y que reproducimos aquí (Figura 4$),{ }^{8}$ se hizo por un original contemporáneo del viaje que ilustra, pues dibujo, colores, adornos y manera de hacer son de aquella época, y la vaguedad en la extensión, trazado, y desembocadura de los ríos, demarcación de lugares, figura de las orillas y costas, etc., etc., corresponden a los inseguros conocimientos que del gran río teníamos aún por los años del primer tercio del siglo XVII. Tengo también por vehementes indicios de que nuestra copia lo es de la planta de Acosta: la dirección del cuerpo del río; la cercanía de sus más remotas cabeceras a la ciudad de San Francisco de Quito, cuyo nombre acababa de tomar; la poca 
importancia que se da a sus grandes afluentes superiores de la derecha, que hubieran llevado su origen lejos de donde entonces se quería que estuviese; las armas de aquella ciudad al pie, como timbre; la preferente indicación del paraje en donde desembarcó la armadilla de Texeira; el número de leguas que se le suponen al río de largo y las 300 desde su mayor angostura a la boca, y otras concordancias con el texto de la relación dirigida al conde de Castrillo fáciles de apreciar a la simple lectura.

Figura 4. Reproducción del mapa de Benito de Acosta en el libro de Jiménez de la Espada (1889)

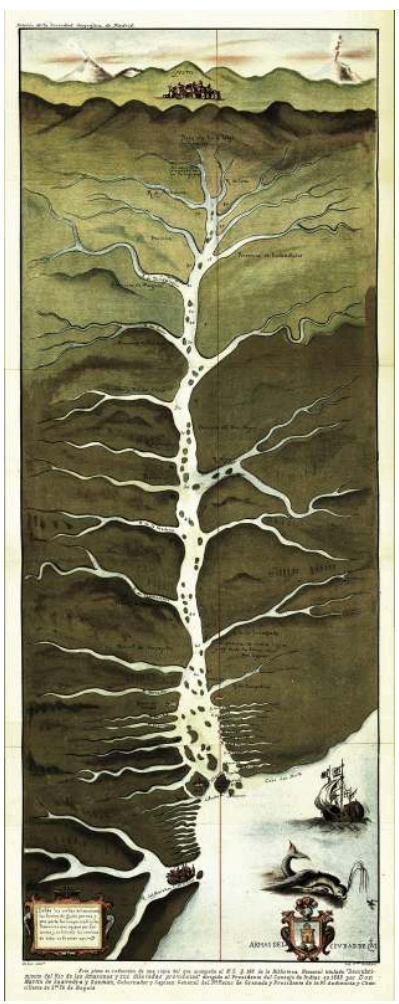

"Exacta y bellísima copia obra y obsequio de mi inolvidable y buen amigo don Germán de Aguirre", encomendada por Jiménez de la Espada para su libro y para el Boletín de la Sociedad Geográfica de Madrid. Es esta la versión más conocida y reproducida de este mapa y la misma estudiada por el Barón de Rio Branco y por Jaime Cortesão (véase en este mismo número de Terra Brasilis un texto clássico de Cortesão, con otra versión de este mapa, atribuida a Texeira y Acosta). Su leyenda reza: "Este plano es reducción de una copia del que acompaña al M. S. Q.196 de la Biblioteca Nacional titulado "Descubrimiento del Río de las Amazonas y sus dilatadas provincias", dirigido al Presidente del Consejo de Indias en 1639 por Don Martín de Saavedra y Guzmán, Gobernador y Capitán General del No Reino de Granada y Presidente de la R' Audiencia y Chancillería de Sª Fe de Bogotá".

Fuente: Biblioteca Digital Hispánica - Biblioteca Nacional de España. Disponible en: http://bdh.bne.es/ bnesearch/detalle/bdh0000056812

Para decir verdad, a mí particularmente me basta con los indicios apuntados y el aserto del P. Laureano; pero existe otro dato que no sólo confirma mi parecer, sino que lleva hasta la sospecha de que los mapas de mano presentados al Consejo de Indias por el P. Acuña con su Nuevo descubrimiento eran copias algo modificadas del que no vino con la relación del P. Rojas leída por Pinelo. Este laborioso jurisconsulto y eruditísimo literato, al cotejar dichos mapas con otro que tenía de diferente origen, buscando la más exacta y perfecta descripción del río de las Amazonas, ${ }^{9}$ da tales señas de ellos (como las leguas que miden su desembocadura y su parte más estrecha y la denominación de sus principales tributarios), que parece que tiene uno delante de los ojos el facsímil que 
publicamos, salvo las omisiones y errores de nombres que al componer su original se cometieron indudablemente.

El mapa de Benito de Acosta anda lejos, muy lejos de la perfección, pero, en conjunto, es el menos malo de los bosquejos gráficos del gran río trazados hasta el viaje de Texeira, de que tengo noticia. Con las Cartas de Indias corre uno hecho poco después de 1554, que a lo fantástico de sus líneas une la absoluta carencia de nombres (Figura 5).

Figura 5. Mapa de los ríos Amazonas, Esequivo o Dulce y Orinoco y de las comarcas adyacentes

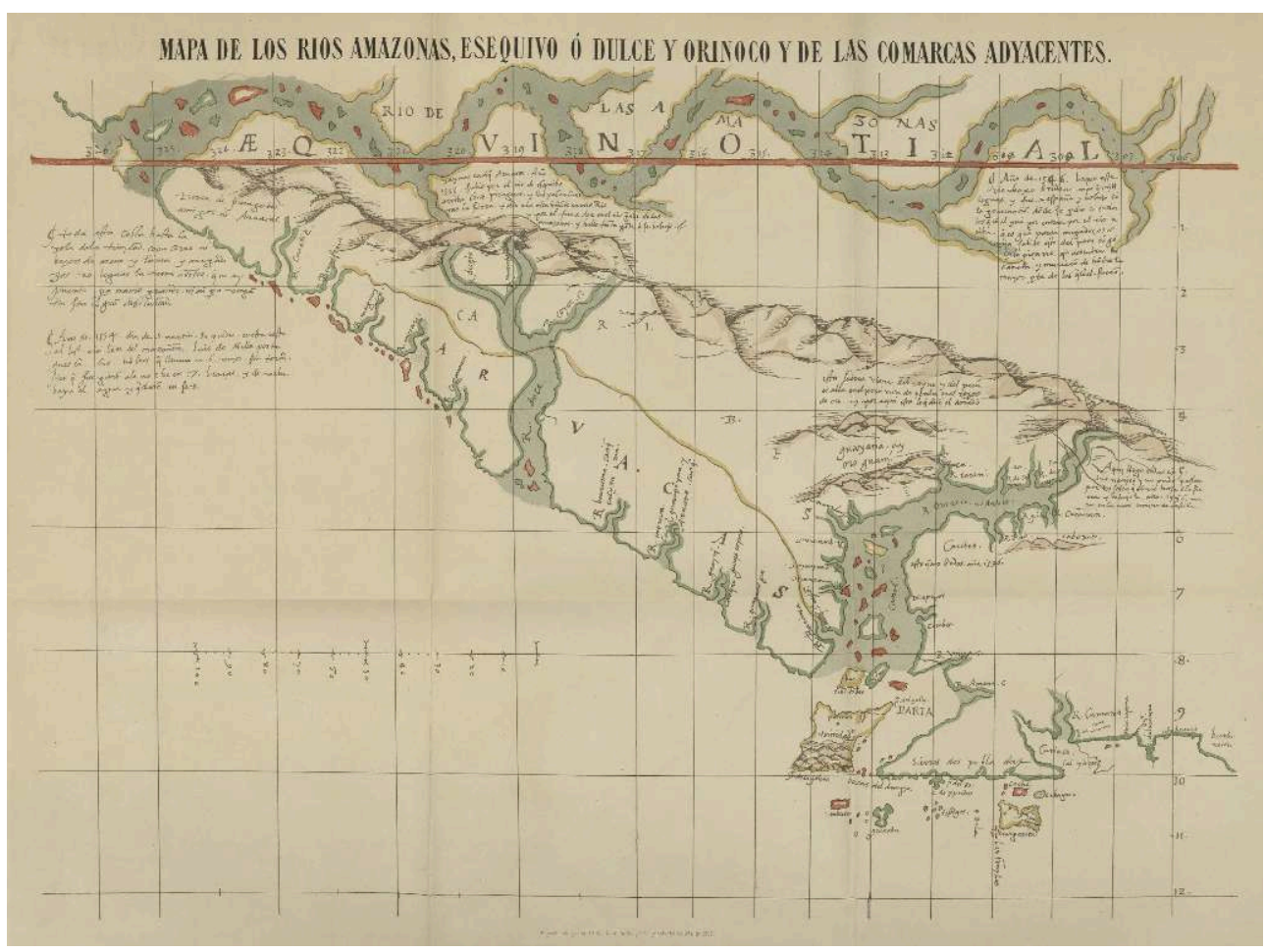

Incluido en las Cartas de Indias (Madrid, Ministerio de Fomento, 1877). Reproducido por la litografía del Instituto Geográfico y Estadístico de España para dicha publicación.

Fuente: Biblioteca Virtual de Andalucía. Disponible en: http://www.bibliotecavirtualdeandalucia.es/ catalogo/es/consulta/registro.cmd?id=1039364

En un lujoso atlas que fue del duque de Alba, marqués de Villafranca, ${ }^{10}$ a la carta núm. 13, pintada probablemente como su compañera de la América Meridional (núm. 10) en 1562 (Figura 6), es imagen del río de las Amazonas una especie de diagrama, compuesto de un lago de margen ondulosa de donde nace una línea serpentina con las curvas simétricas, regulares y cada vez más espaciosas, sencilla en sus dos tercios superiores y desde allí doble y limitando un cauce que se ensancha a medida que se acerca a la costa y concluye por abrir en el mar en forma de bocina, dentro de cuyo pabellón se ven diseminadas a capricho multitud de islas como un puñado de gragea. En la parte exterior de cada vuelta hay un trazo o apéndice en figura de gancho: son los afluentes. Es mudo como el de las Cartas de Indias y lleva junto a la desembocadura la siguiente nota con más equivocaciones que palabras: "Este río descubrió desde su nacimiento Francisco de Orellana año de 1544." 
Figura 6. El río Amazonas en el atlas náutico de Bartolomé de Olives (1562)

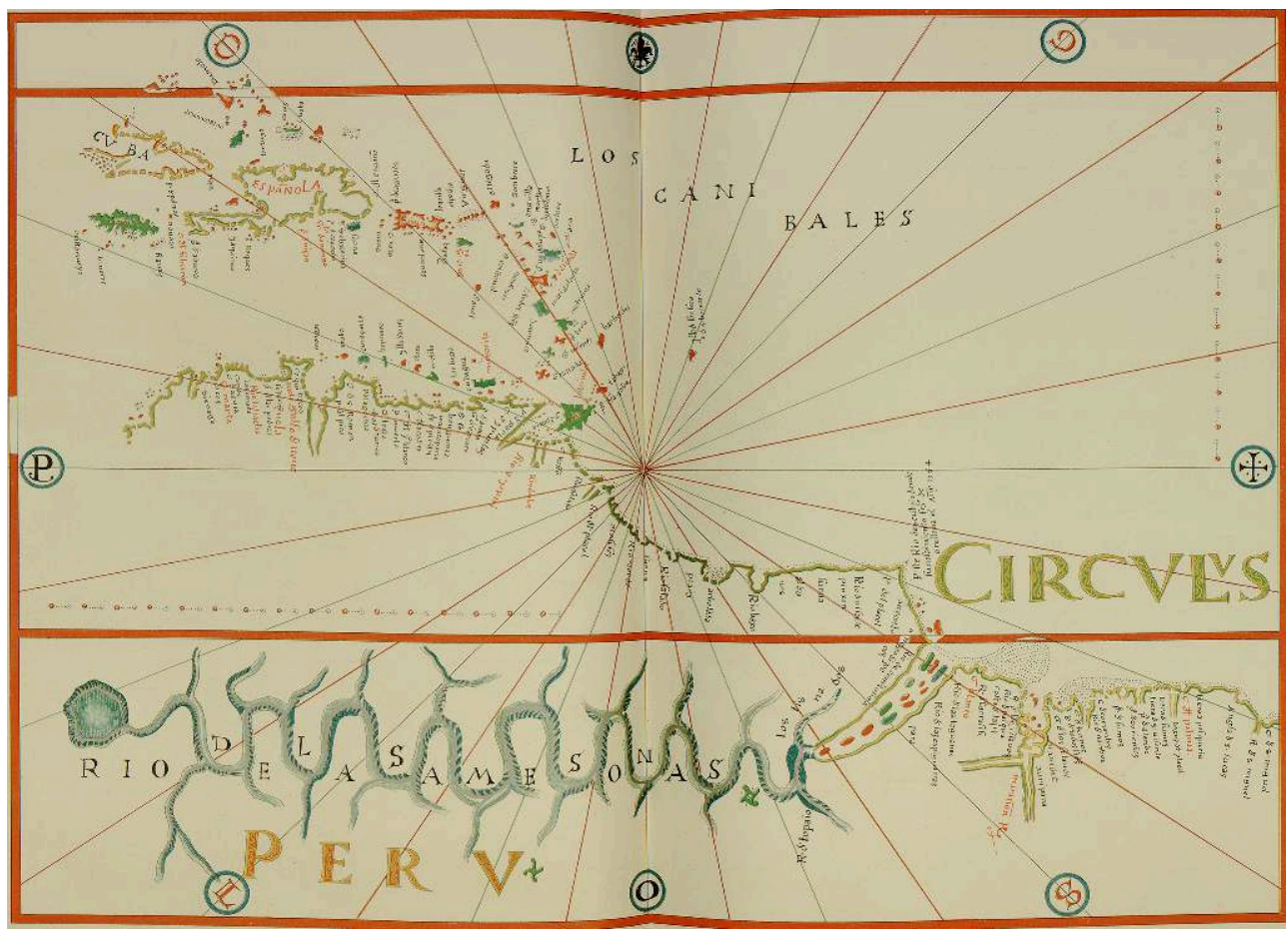

El original se encuentra conservado en la Biblioteca Apostólica Vaticana, donde se encuentra pobremente digitalizado. Fue reproducido por el Barón de Rio Branco en el atlas que acompaña la primera de sus dos memorias presentadas al arbitraje suizo con respecto a la cuestión de límites con la Guyana: Frontières entre le Brésil et la Guyane française. Atlas contenant un choix de cartes antérieures au traité conclu à Utrecht le 17 avril 1713 entre le Portugal et la France. Annexe au Mémoire présenté par les Etats Unis du Brésil au gouvernement de la Confédération Suisse, arbitre choisi selon les stipulations du traité conclu à Rio de Janeiro, le 10 avril 1897, entre le Brésil et la France. Paris, A. Lahure, 1900. Mapa 15.

Fuente: Manioc : Bibliothèque Numérique Caraïbe, Amazonie, plateau des Guyanes. Disponible en: http://www.manioc.org/patrimon/HASH0155dee189cd5f8d3bb8d7da

Harto conocido es el Mapamundi de Ortelio grabado por los años de 1587, en que el Marañan y el Orellana corren como dos ríos distintos desde sus nacimientos hasta el mar y muy separados uno de otro, excepto en la parte media en que se unen o cruzan como los ramos de una $\mathrm{X}$ (Figura 7). 
Figura 7. Fragmento del mapa Americae Sive Novi Orbis, Nova Descriptio de Abraham Ortelius (1587)

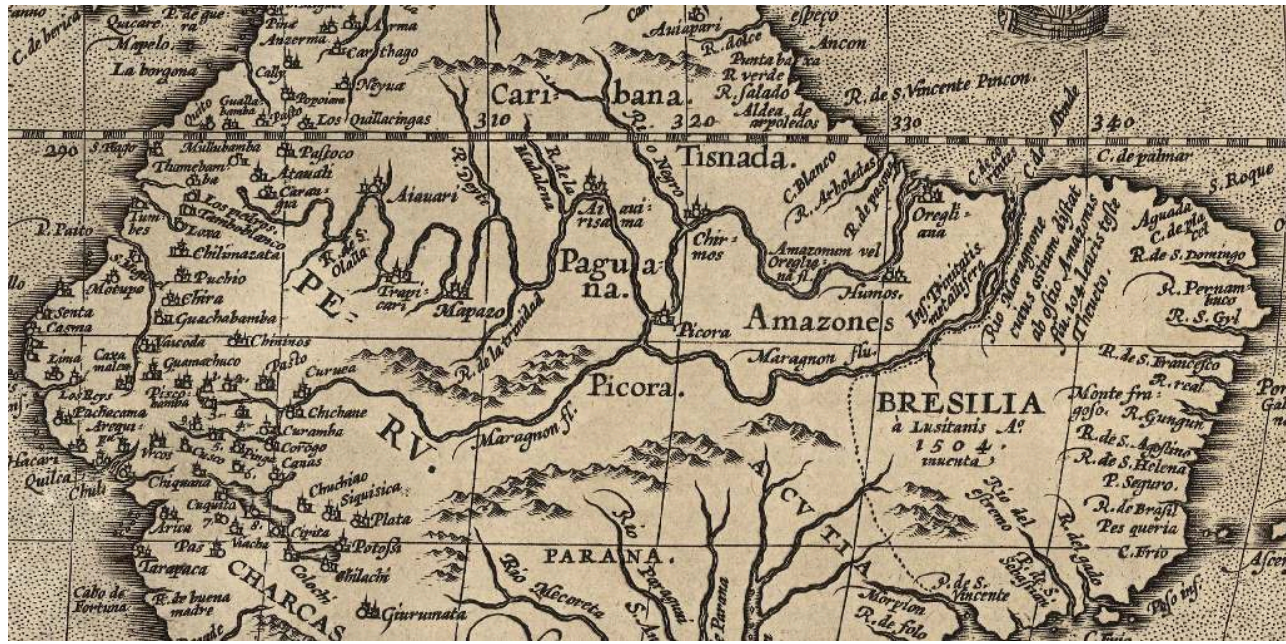

Este mapa de América corresponde a la descripción de Jiménez de la Espada. Sin embargo, en el Typus Orbis Terrarum, también de 1587, y de hecho en la mayoría de los mapas de Ortelius, anteriores y posteriores a éste, el río Marañón entra en el Amazonas.

Fuente: David Rumsey Map Collection. Disponible en: https://www.davidrumsey.com/luna/servlet/s/ h87j5y

12 Más ajustado a la verdad que los antecedentes, aunque sólo en los principios y parte media de su curso, es el que publicó en Sevilla el año de 1608 el licenciado Diego Méndez, cosmógrafo del Perú y capellán de las monjas de la Encarnación de Lima, en su Corografía peruana, dedicada al conde de Lemus, presidente del Consejo de Indias; en cambio, desde el comienzo de su tercio inferior se divide en dos grandes brazos o ríos distintos y cada cual con su nombre, imitando el Mapamundi de Ortelio. ${ }^{11}$ Este gravísimo error y confusión geográfica subsiste en la carta de la América Meridional, que, tomando la de Méndez por modelo y corrigiéndola, y añadiéndola con el estrecho de Le Maire, compuso Lucas de Quirós, cosmógrafo del Perú e hijo de Pedro Fernández de Quirós, por mandado del virrey príncipe de Esquilache, el año 1618 y se halla de mano en pergamino con el Discurso primero del tomo primero de la Noticia general del Perú MS. de Francisco López de Caravantes (Figura 8). 
Figura 8. Description Corographica de las provincias del Piru Chile nuevo Reyno i tierra firme - Lucas de Quirós cosmógrafo Mor. del Mar del Sur (1618)

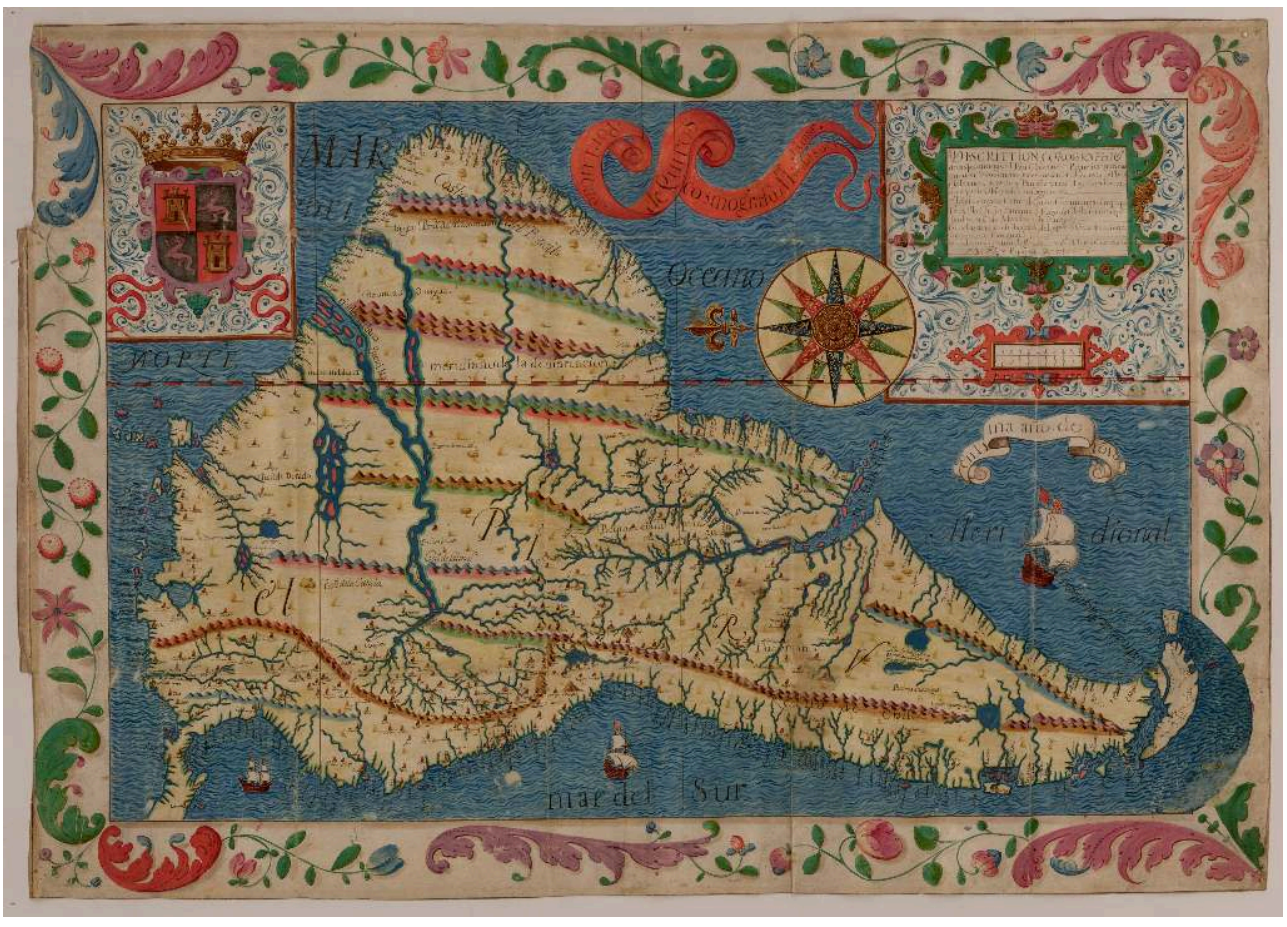

Acompaña a la Noticia general de las provincias del Pirú, Tierra Firme y Chile de Francisco López de Caravantes

Fuente: Real Biblioteca del Palacio Real de Madrid. Disponible en: https://www.realbiblioteca.es/es/ node/286\#\&gid=1 \&pid=6

13 Únicamente, a juicio de Pinelo, aventaja con mucho a la obra de Acosta, en la parte comprendida entre la bifurcación del río y su desagüe, la planta que de esa misma parte trazó el cosmógrafo portugués Pedro Texeira (Figura 9), ${ }^{12}$ acerca de la cual, comparándola con las presentadas por el P. Acuña al Consejo, opina,

que es la verdadera y cierta, por ser sacada de las noticias que le darían los portugueses, que ha tantos años que habitan en el Pará y han reconocido la mayor parte de las islas y canales que en aquella maravillosa ensenada se incluyen; con que conviene por mayor lo que por relaciones holandesas pone Juan de Laet (libro 17) en la tabla de la Guayana [Figura 10] y explica en letra, si bien con algunas dudas que no puedo resolver. ${ }^{13}$ 
Figura 9. Fragmento del mapamundi de Pedro Teixeira Albernaz (1634)

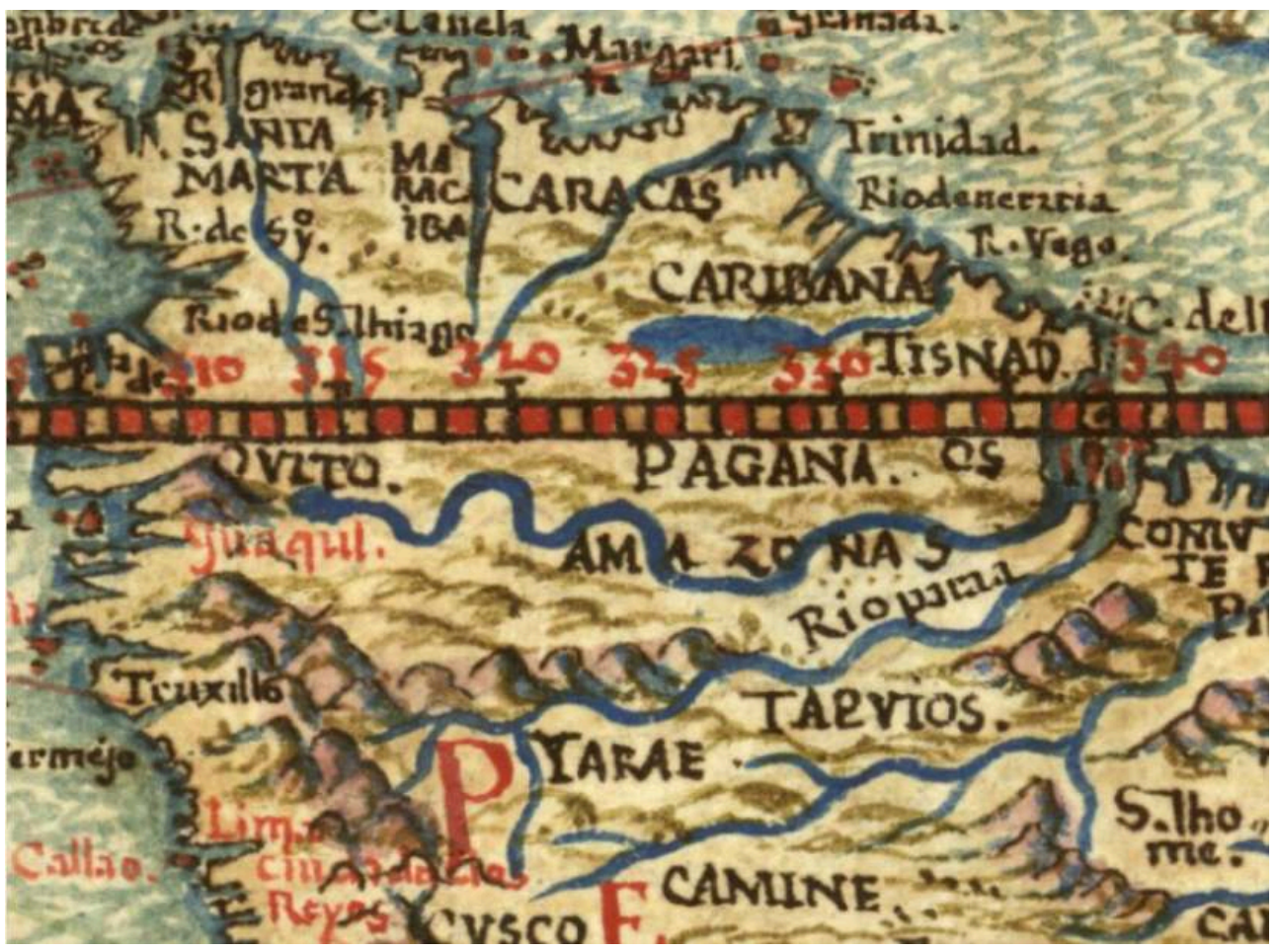

De su atlas titulado Descripción de España y de las costas y puertos de sus reynos. Tal vez Pinelo esté confundiendo a Pedro Teixeira Albernaz con su hermano João, autor de diversos mapas del Brasil y de la región de la desembocadura del río Amazonas.

Fuente: Biblioteca Nacional de Áustria. Disponible en: https://onb.digital/result/10DD84BB 
Figura 10. Gvaiana siue provinciæ intra rio de las Amazonas atque rio de Yviapari siue Orinoqve Joannes de Laet (1640)

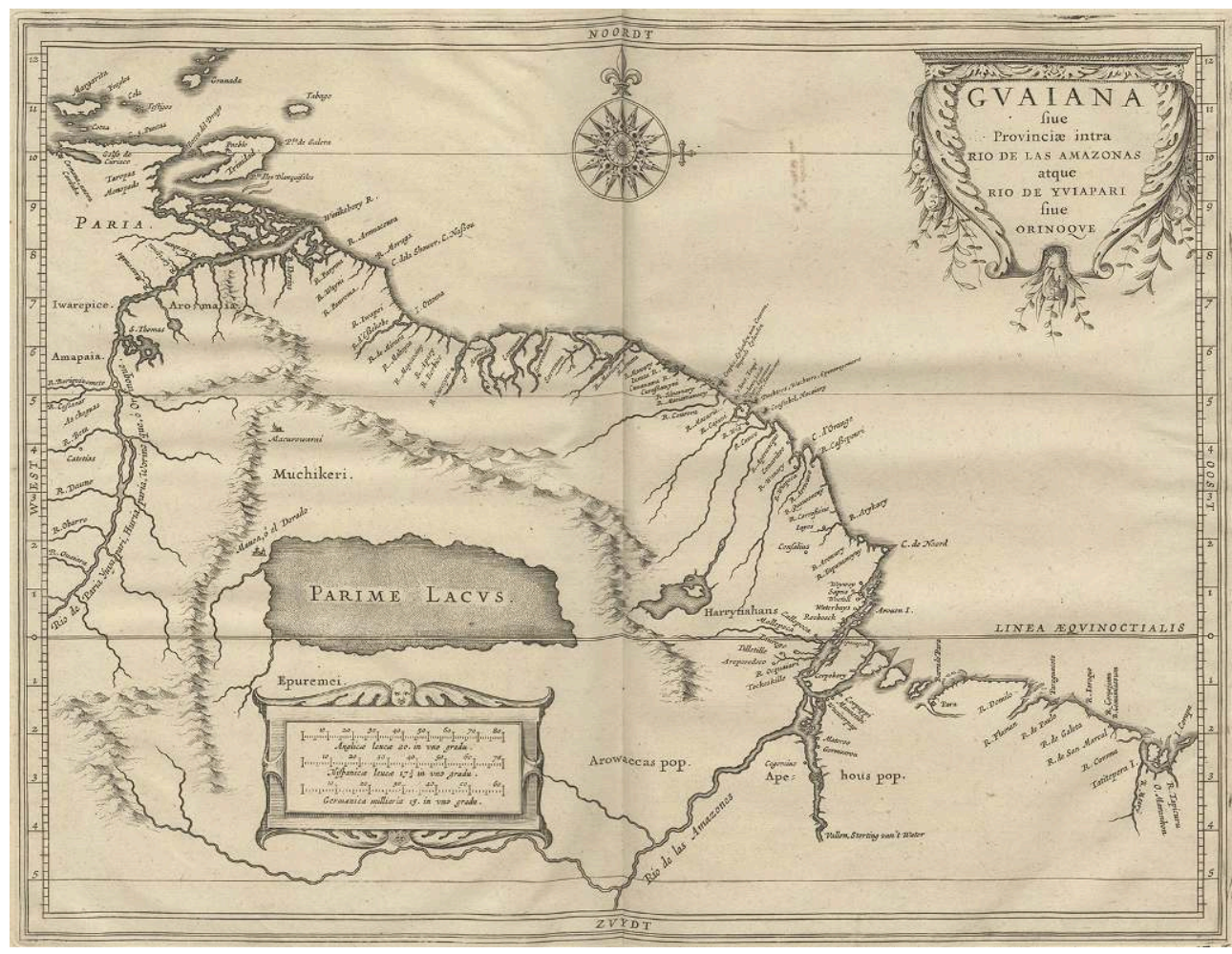

El original holandés Beschrijvinghe van West-Indien de Joannes de Laet (1630) puede encontrarse en Internet Archive, digitalizado por la John Carter Brown Library (<https://archive.org/details/ beschrijvingheva00laet>). Preferimos el mapa de la versión francesa (L'Histoire du Nouveau Monde ou description des Indes occidentales), dado que la encuadernación de esta última permitió una mejor digitalización en el doblez de la página.

Fuente: Manioc : Bibliothèque Numérique Caraïbe, Amazonie, plateau des Guyanes. Disponible en: http://www.manioc.org/images/BBX17007-0646i1

Y luego en el capítulo siguiente dice [Pinelo]:

$\mathrm{O}$ por el mismo tiempo ${ }^{14} \mathrm{o}$ algunos años después ${ }^{15}$ fue a reconocerle [el Marañón de Castilla, o río de las Amazonas] por orden de S. M. Antonio Vicente Cochado, piloto mayor de Pernanbuco, y halló, que así la boca como las demás que al Occidente della salen hasta la Punta del Norte, son todas de solo un río, que 130 leguas por la tierra adentro, casi en $7^{\circ}$ australes, habiendo llegado allí con solo un cuerpo o corriente, se divide luego en dos brazos principales y cada uno dellos en otros muchos, causados de la multitud de islas que forman allí un hermoso archipiélago. De los dos brazos, el oriental es menor y con más islas hasta cerca de la boca, que, juntándose casi todo, sale ancho y limpio y es el que comúnmente se llama el Gran Pará. El occidental, aunque en su origen es mayor y viene recogiendo muchos ríos que entran de la Tierra Firme, a que viene arrimado, padece luego tantas divisiones por islas que se le interponen, que al desaguar en el mar no es tan grande como el otro, porque sale por muchas canales o bocas. Estos dos brazos desde su división forman otra bahía o ensenada como la del Marañón de Portugal, que en esto se parecen los dos, aunque ésta es mucho mayor, y tanto, que en sola ella se pudiera incluir casi toda España. De esta ensenada, según la relación del piloto Cochado y otras que tuvo, hizo una planta don Pedro Texeira [Figura 11], cosmógrafo mayor de Portugal, que ha llegado MS. á mi poder. Y porque con ella se demuestra bien la grandeza deste río y sus bocas y verdadera situación, me pareció reducirla a punto menor y ponerla por principio de la descripción deste río, y es esta [aquí la figura]. Por esta 
planta se prueba y conoce ser este río el mayor del Orbe. A todas sus bocas reducidas a una llaman los naturales Curupapp. ${ }^{16}$

Figura 11. Descripção dos rios Parâ, Curupa e Amazonas. Descuberto e sondado por mandado de Sua Ma. ${ }^{\text {gde }}$ Por Ant. ${ }^{\circ}$ Vicente, patrão de Pernãobuco - João Teixeira (1630)

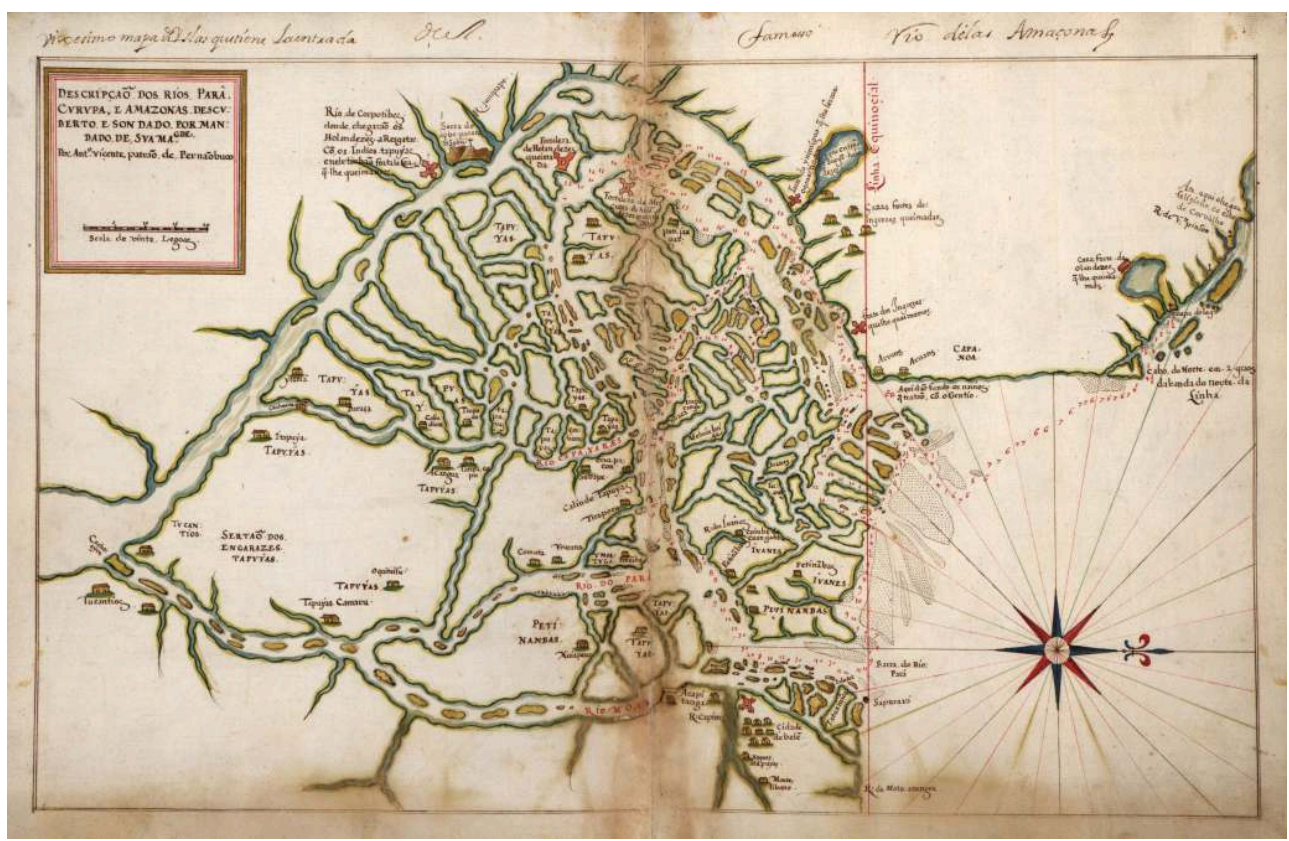

Hace parte de las Taboas geraes de toda a navegação. Divididas e emendadas por Domieroni Mo de Attayde com todos os portos principaes das conquistas de Portugal. Delineados por loão Teixeira, Cosmógrapho de Sua Magestade (1630). Los originales de Antonio Vicente Cochado se encuentran en la Biblioteca Nacional de Río de Janeiro. Véase en este mismo número de la Terra Brasilis la reproducción, con mapas, del capítulo clásico de Jaime Cortesão sobre la cartografía amazónica del siglo XVII. León Pinelo, ciertamente, confunde a Pedro con João Teixeira Albernaz.

Fuente: Library of Congress Geography and Map Division. Disponible en: https://www.loc.gov/ resource/g3200m.gct00052/?sp=23

El no citarse en la anterior noticia ni el mapa del Brasil que Juan Bautista Gessio tuvo presente al escribir su breve descripción de aquella tierra en 1579, ni la carta de los puertos del río de las Amazonas y costa hasta la isla Margarita, copia del exacto y verídico original holandés, que con su explicación y otros avisos secretos llegó a poder del duque de Lerma y pasó al Consejo de Indias en 27 de junio de 1615, indican que ya faltaban en dicha oficina, cuando Pinelo la redactaba. Después no creo que hayan parecido por ninguna parte.

El P. Ruíz de Montoya, con el propósito quizá de demostrar las exageraciones de su hermano Cristóbal de Acuña, trazó también un mapa general del Brasil incluyendo el río de las Amazonas. Viólo Pinelo; yo no lo conozco. ${ }^{17}$

Daré fin a estos ya demasiado extensos Preliminares con la nota bibliográfica de nuestro manuscrito. Es un tomito en $4^{\circ}$ de 31 fol. numerados, con más la portada y otra hoja con el encabezamiento de la dedicatoria dentro de un escudo lambrequinado y encimado de las armas del conde de Castrillo. Copia contemporánea, de letra esmerada y clara, y las páginas con doble perfil por marco y un adorno repetido en la parte superior de cada una. Al fin otro adorno imitando los de imprenta. La portada lleva este título: Descubrimiento del río de las Amazonas y sus dilatatadas (así) provincias; y antes de comenzar la relación hay este otro: Relación del descubrimiento del río de las Amazonas y [hoy] San Francisco del Quito, y declaración del mapa donde está pintado; que corresponden a 
los dos artículos ya citados del Epítome de la biblioteca Pinelo-Barcia. El mapa mide $1^{\mathrm{m}}$, 13 x 0,41. Está reproducido exactamente en nuestro facsímil, sin exceptuar las equivocaciones de nombre que, a mi juicio, cometió su autor al copiarlo del original, o de otra copia, en donde - principiando desde arriba y por la orilla derecha- diría probablemente: Provincia de Omaguas y no de Maguas; no estaría repetido río del Cusco, y río y provincia de Tapinambas serían de Tupinambás. Y en la orilla izquierda, en vez de Ginipago, Cuma mexin y Tapayas (en la isla de Ioanes), se leería Ginipapo, Cumá merin y Tapuyas. No me hago cargo de las omisiones, algunas evidentes, en mi concepto; ni me detengo en apuntar la sinonimia, que es obra fácil con ayuda de los mapas modernos y del pasado siglo, especialmente el clásico y justamente celebrado que compuso y grabó don Juan de la Cruz Cano y Olmedilla el año de 1775 (Figura 12).

Figura 12. Detalle del Mapa Geográfico de América Meridional de Juan de la Cruz Cano y Olmedilla (1775)

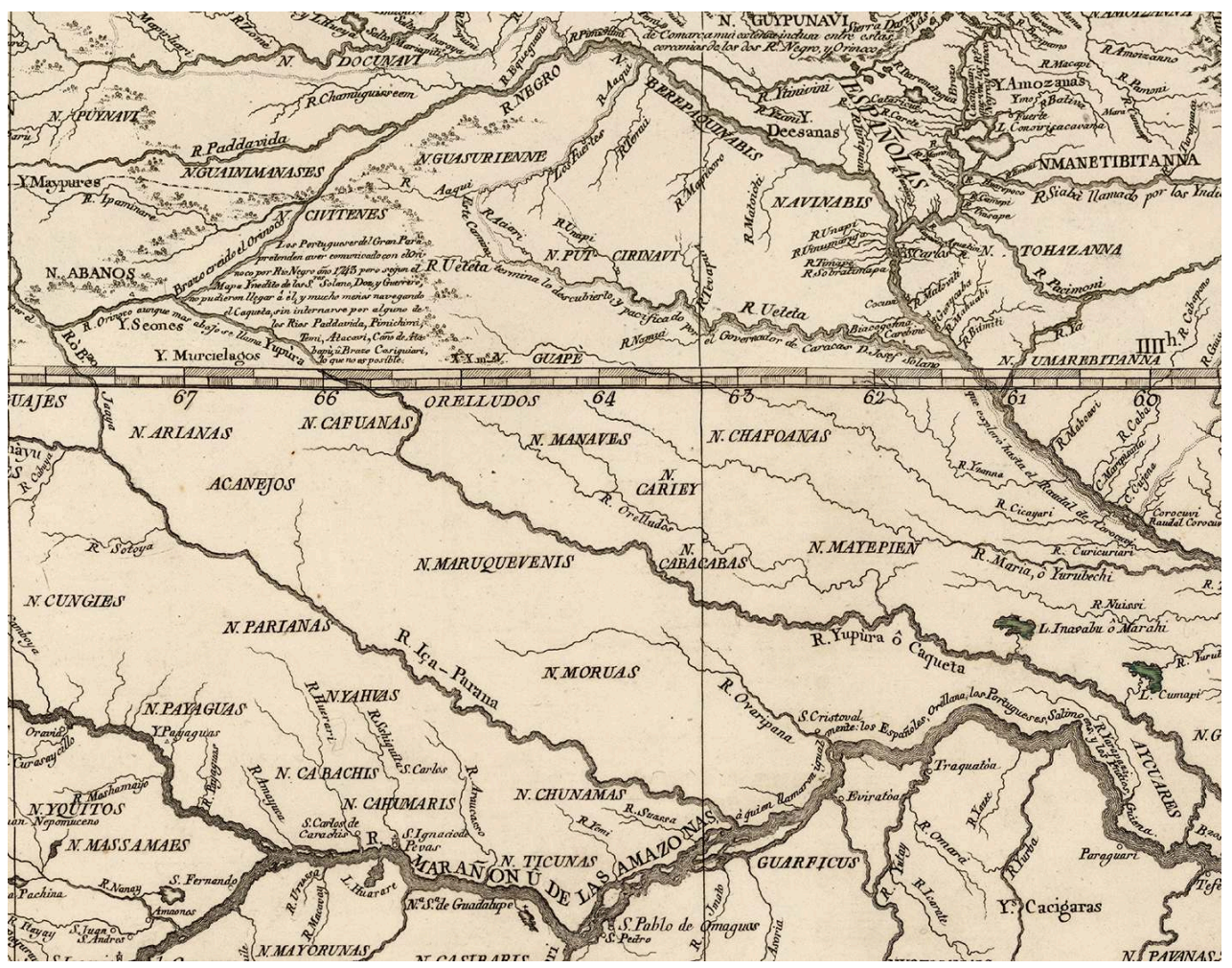

Para Jiménez de la Espada, en el mapa de Cano y Olmedilla figura la idea del piloto Acosta sobre la ligación entre el Amazonas y el Orinoco a través del río Negro (expresada con la leyenda "Brazo Casiquiari que une los $\mathrm{R}^{\mathrm{s}}$ Negro y Orinoco", en la parte superior derecha de este recorte), comunicación "complicada notablemente [por este cartógrafo] con enlaces del Río Negro con el Caquetá y de este con el Iza o Putumayo por medio de bifurcaciones imaginarias".

Fuente: David Rumsey Map Collection. Disponible en: https://www.davidrumsey.com/luna/servlet/s/ $7 \times 21$ pe

[A continuación incluimos, para finalizar, la anotación (ordinal F, p. 107-108) de Jiménez de la Espada al siguiente trecho del manuscrito de Alonso de Rojas: "El piloto mayor, de quien después hablaremos, que navegó dos o tres días por este río Negro, dice que según la noticia que pudo tener de algunos indios, nace este río de unas sierras vecinas al Nuevo Reyno de Granada y que en su origen se divide en dos brazos; el uno de ellos con el nombre de río Negro desagua después de largo curso en el de las Amazonas, 
el otro viene a desaguar en el mar del Norte a vista de la isla de la Trinidad, y piensan que este río es el famoso río Orinoco" (p. 74-75).]

(F). - Estas noticias e hipótesis del piloto de la expedición de Teixeira, Benito de Acosta, se consignaron gráficamente en el mapa rotulado: Terre Ferme ou sont les Governations, ou Gouvernments de Terre Ferme, Cartagene, Ste Marte, Rio de la Hacha, Venezuela, Nouvelle Andalousie, Popayan, Nouveau Roime de Grenade etc. Tirée de divers Autheurs, et de divers Relations. Par N. Sanson d'Abbeville, Géographe ordinaire du Roy. A Paris. Chez Pere Mariette, Rue S. Iaque à L'Esperance. Avec privilege du Roy pour vingt ans, 1656 (Figura 13).

Figura 13. Terre Ferme, Nicolas Sanson (1656)

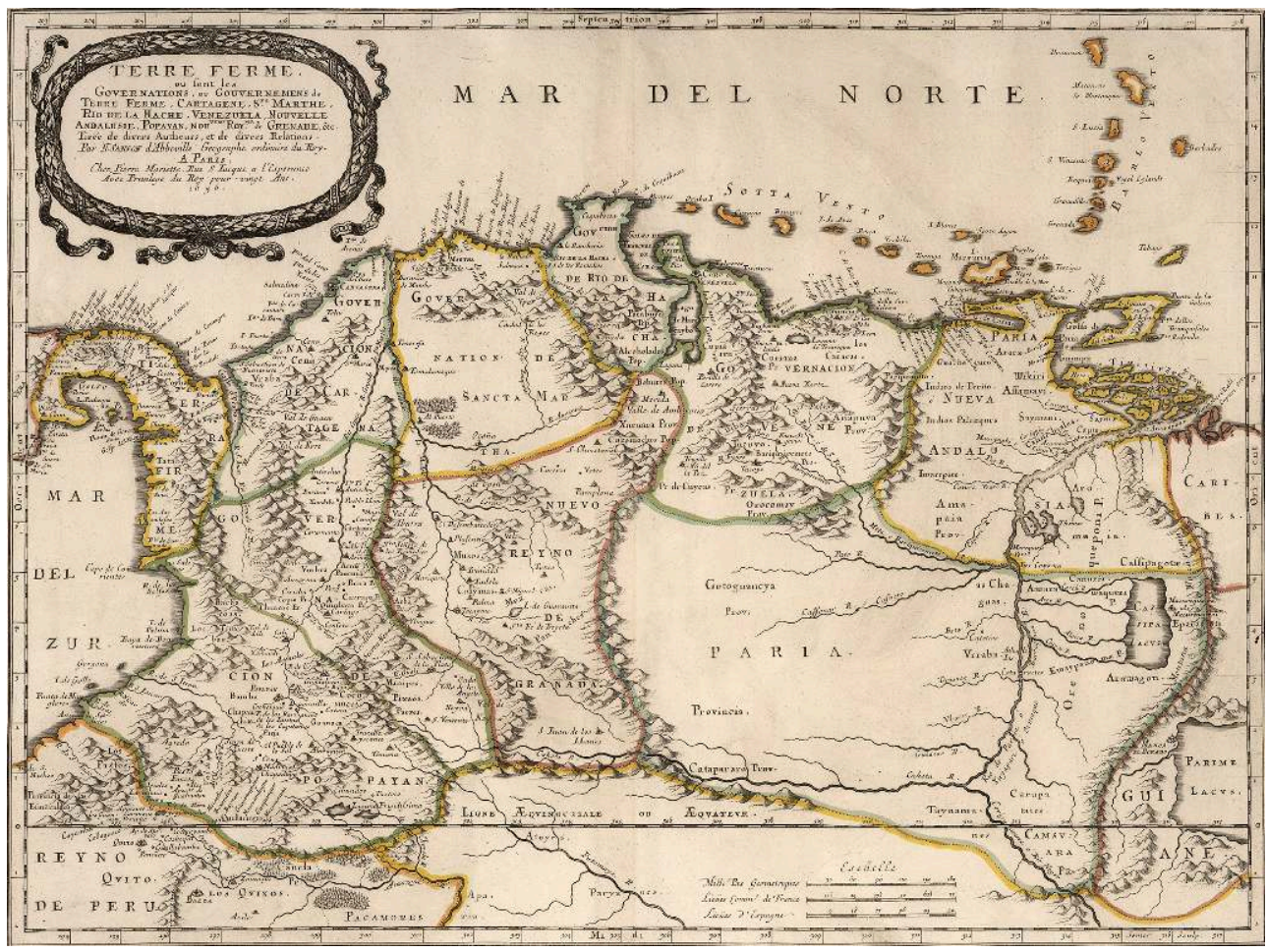

Parte del atlas titulado Cartes et Tables de la Geographie Ancienne et Nouvelle (1697-1709). La

bifurcación indicada por Benito de Acosta y registrada en su manuscrito por Alonso de Rojas y que menciona Jiménez de la Espada, se aprecia en la parte inferior derecha. Hacia el norte se desprende el "Rio de Paria ó Yuyaoari ó Orinoque" y hacia el lado opuesto se desvía el "Coriguacure ó Rio Negro". Fuente: David Rumsey Map Collection. Disponible en: https://www.davidrumsey.com/luna/servlet/s/ 8smvez

El P. Cristóbal de Acuña, que conoció la relación que publicamos, quiso enmendar las noticias de Acosta, y cometió dos errores más crasos que el del piloto portugués, afirmando primero categóricamente que de ningún modo podía ser el Orinoco el río que comunicaba con el Amazonas, y suponiendo después que el río enlazado con este por medio del Negro era el Dulce o Esequivo, o el de Felipe (Oyapoc) (Nuevo descubrimiento, etc., Número 65). La opinión de Acosta es en el fondo la más aproximada a lo cierto. Y notaré como extrañeza geográfica, que aun después de descubierta y comprobada la verdadera comunicación de los grandes sistemas fluviales del Orinoco y del Amazonas por medio del río Casiquiari, figura en el concienzudo mapa de Cano y Olmedilla la idea de Acosta complicada notablemente con enlaces del Río Negro con el Caquetá y de este con el Iza o Putumayo por medio de bifurcaciones imaginarias (Figura 
12); que conservó, no obstante, don Manuel de Villavicencio en su mapa de la República del Ecuador, publicado el año de 1858 (Figura 14).

Figura 14. Detalle de la Carta corográfica de la República del Ecuador de Manuel de Villavicencio (1858)

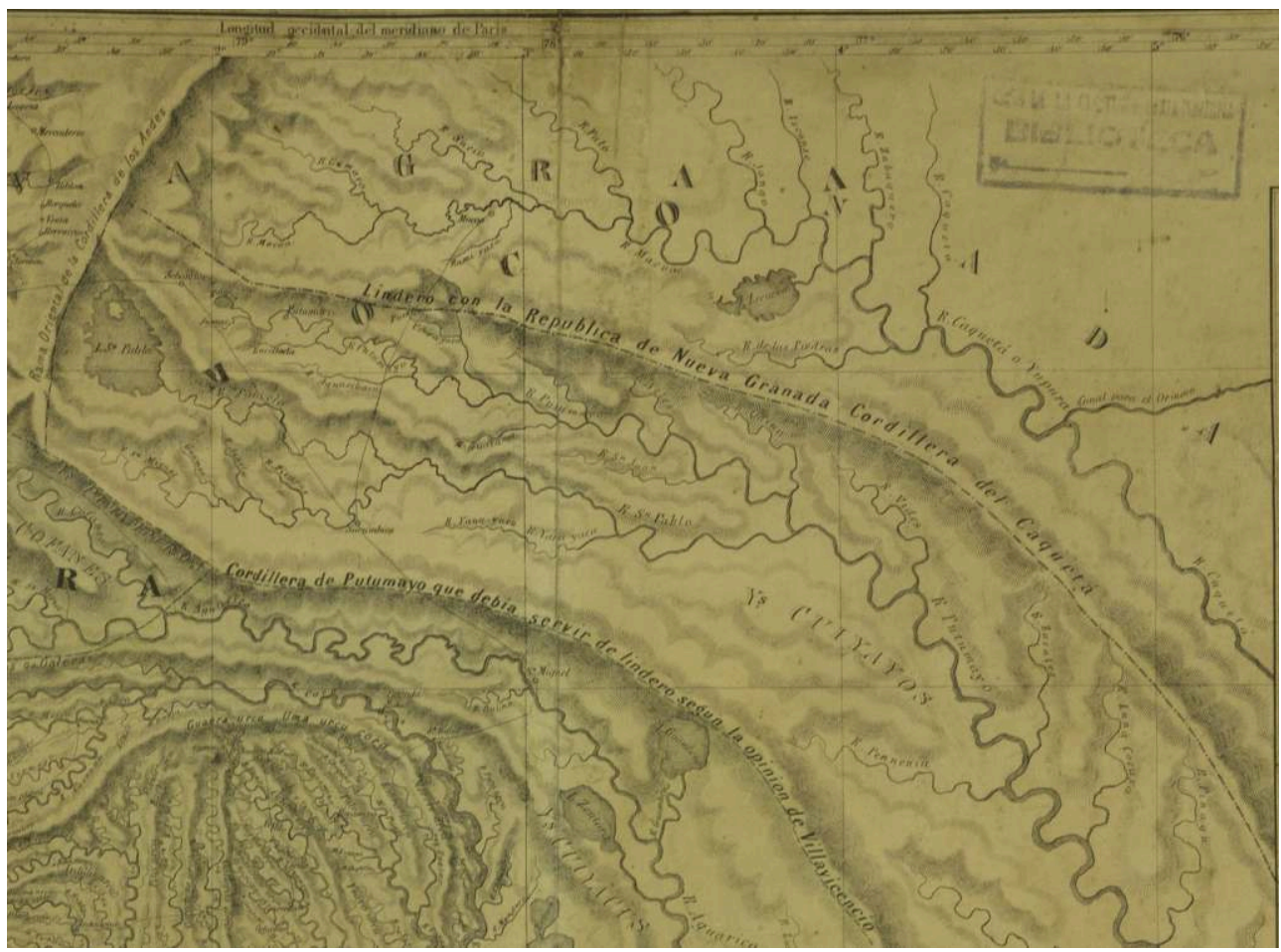

Como notado por Jiménez de la Espada, a la derecha puede verse saliendo del Caquetá un "Canal para el Orinoco"

Fuente: Repositorio Digital - Biblioteca Nacional del Ecuador. Disponible en: http:// repositorio.casadelacultura.gob.ec//handle/34000/17611

\section{NOTES}

1. Así consta del asiento que se tomó con Vicente Yáñez Pinzón en Granada, a 5 de setiembre de 1501, cuyo capítulo 1 dice: "Por cuanto vos fuisteis á vuestra costa con cuatro navíos con vuestros parientes y amigos á descobrir y descobristeis é pusisteis nombre á Santa María de la Consolación é Rostro fermoso [tierras del Brasil], é siguiendo al norueste fasta el rio grande que llamastes Santa María de la Mar Dulce, etc."

2. Hoy ya no existe ni siquiera ese pedazo, que ha desaparecido al encuadernarse nuevamente el ms.

3. En las mismas adiciones consta como obra diferente una Relacion del Descubrimiento del Río de las Amazonas, (oi de San Francisco de Quito) i Declaración del Mapa en que está pintado, Año de 1638 MS fol. en la Librería de Barcia. Es la anterior sin la dedicatoria y documentos preliminares; lo cual prueba que Barcia no vio la que atribuía a don Martín de Saavedra. 
4. Al citar Diego Rodríguez Docampo, secretario del cabildo catedral de Quito, al P. Alonso de Rojas en la Descripción y relación del estado eclesiástico de el Obispado de San Francisco de Quito, hecha por orden del rey (MS. - 1650), dice de él: “De España; profeso, catedrático y perfecto en esta Universidad; gran predicador y sobremanera devoto de la Virgen Ntra. Sra. - Ha sido rector en este Colegio."

5. El ejemplar a que aludo se hallaba hace cosa de dos años en la librería de Murillo, y si mal no recuerdo, lo adquirió S. M. para su biblioteca particular. (N. del A.). En el segundo volumen, p. 691, de la reedición del Epítome de Pinelo realizada por el Marqués de Torre-Nueva (1738), el manuscrito continúa siendo atribuido a Saavedra y Guzmán y catalogado de la siguiente manera: "Descubrimiento del Rio de las Amaçonas, i sus dilatadas Provincias, dedicada al Conde de Castrillo, Presidente de Indias, con vn Mapa mui extenso del Rio, i Navegacion, i la Tierra, M. S. O. en la Libreria del Marqués de la Compuesta, Secretario del Despacho Universal". Disponible en la Biblioteca Digital Hispánica de la Biblioteca Nacional de España <http://bdh.bne.es/bnesearch/ detalle/bdh0000008931>. (N. del E.).

6. El padre franciscano Laureano de la Cruz, en su Nuevo descubrimiento del rio de Marañón llamado de las Amazonas, escrito en 1653 e impreso en 1900, afirma lo siguiente (p. 70 de la edición impresa): "El Piloto de la armada portuguesa, á pedimento de aquellos señores hizo un mapa de nuestro gran río como persona que lo había marcado y tanteado bien, como ya dijimos, que fue de mucho gusto para todos los que lo vieron. Yo lo vi muchas veces y cotejándolo con su original, me parece está cabal, y verdadero". Tanto el original manuscrito como la edición impresa se encuentran en la Biblioteca Digital Hispánica de la Biblioteca Nacional de España. (N. del E.).

7. Esta parte es confusa. Algunas páginas atrás (p. 39-40), Jiménez de la Espada había ya apuntado un trecho de Montesinos en el que éste declara haber sido consultado por el virrey del Perú, conde de Chinchón -a quien las autoridades quiteñas habían trasladado la decisión de qué hacer con los visitantes portugueses-, y según el cual el mismo Montesinos habría respondido a la consulta con un comentario acerca de la relación enviada a Chinchón por Pedro Teixeira, "unas noticias, derrotero y mapa". Jiménez de la Espada cita aquí la obra de Montesinos Ophir peruano, Lib. 1, cap. 16. Debe tratarse del Ophir de España, obra editada por el mismo historiador en 1882, en la cual, sin embargo, no fue posible encontrar el fragmento citado. (N. del E.).

8. Por una exacta y bellísima copia obra y obsequio de mi inolvidable y buen amigo don Germán de Aguirre.

9. En los capítulos IX y X del Libro 5o del Paraíso en el Nuevo Mundo.

10. Hoy en la biblioteca del Depósito hidrográfico.

11. Aparentemente no sobrevive ningún ejemplar de la Corografía peruana de Diego Méndez a que alude el autor. (N. del E.).

12. Confundido en la Bibl. marit. española de Navarrete con Pedro Texeira, capitán mayor del Perú (así, por Pará), y con el otro portugués del mismo nombre que viajó por Persia. (V. Relaciones geográficas de Indias. - Perú. - Tomo I, pág. LXXXI, nota).

13. L. c., cap. IX.

14. De la fundación de la ciudad del Pará y primera exploración portuguesa del Amazonas al mando de Francisco Caldeira de Castelbranco, a los principios del año 1616.

15. Fue por el mismo tiempo, y así lo dice el capitán Andrés Pereira, que estuvo en la fundación de Pará con Francisco Caldeira. (V. su Relação do que ha no grande río, etc.).

16. L. c., cap. X. La planta, desgraciadamente, era una de las que faltaban en el original del Paraíso, cuando por los años de 1779 se sacó la hermosa copia -única que conozco-que se conserva en la Bibl. particular de S. M. (N. del A.). No fue posible encontrar una copia digital del Paraíso en el Nuevo Mundo de Pinelo para verificar la existencia del mapa en esta obra. (N. del E.).

17. No fue posible localizar ninguno de los mapas mencionados por Jiménez de la Espada en estos dos párrafos. Cuanto al mapa holandés, existen diversos mapas de cartógrafos de todas las nacionalidades encuadrando el litoral atlántico desde la desembocadura del Amazonas hasta la 
isla de Margarita. Varios ejemplos pueden verse en los dos atlas del Barón de Rio Branco anexos a sus memorias relativas al diferendo limítrofe con la Guyana francesa. (N. del E.).

INDEX

Geographical index: Rio Amazonas, Amazônia

Chronological index: $1637-1639$ 